\title{
Seeing the smaller picture
}

\section{Advances in imaging techniques are transforming microbiology into a science that is rich in visual imagery, harking back to biology's pre-darwinian origins, explains Martin Kemp.}

Most sciences go through visual and non-visual phases. There are times when attempts to visualize and represent nature stand at the cutting edge. At others, measurement, statistics and algebra hold sway. The two modes are cyclical. Visual phases are often driven by the advent of technologies that allow us to travel optically into new realms, minute or vast.

Until Charles Darwin (1809-1882), biology in its macro form was the most visually rich of sciences. But Darwin's visual austerity was extreme. No pictures are included, for example, of the domestic pigeons that played a starring role in chapter 1 of $O n$ the Origin of Species (1859). This omission must be seen in part as a reaction against the elite picture books that dominated natural history at the time. Darwin's contemporary, Gregor Mendel, with his background in physics and statistics, used numbers in his work on inherited traits in plants.

Today's biology is again embracing the visual. Writing in his blog Small Things Considered (http://tinyurl.com/3w3gx2) for the American Society for Microbiology (ASM), Moselio Schaechter, a former ASM president, has hailed the advent of a brave new visual world in 'small biology.' "Not so long ago, it would have seemed implausible that biology would return to its origins as a visual science," he notes. "Some of the most fundamental work done now once again involves seeing shapes and forms ... Nowadays, mind-blowing insights come from seeing with your own eyes."

The illustration (pictured) accompanying Schaechter's blog is one of the many brilliant drawings of the shells of foraminifera made by Christian Gottfried Ehrenberg (1795-1876), a number of which were published in his Mikrogeologie of 1854. A close colleague of Alexander von Humboldt, Ehrenberg pioneered the study of microscopic fossils. His drawings exhibited the minute developmental geometries that inspired the illustrations of Ernst Haeckel and D'Arcy Wentworth Thompson half a century later. But the immediate future of biological science did not lie with such picturing.

The ASM, which dates back to 1899 , proclaims Louis Pasteur, Robert Koch, Alexander Fleming, Antonie van Leeuwenhoek, Joseph Jackson Lister, William Jenner and Jonas Salk as its progenitors. Of these heroes, only the great microscopist van Leeuwenhoek (16321723) used pictures as a major tool.

As Schaechter combatively puts it, "Many of the founding fathers of modern biology (read molecular biology) were physicists who were used to abstractions and numbers and didn't have the urge to look at anything. Others who should have known better were probably cowed or seduced by these amazing people."

A new world of structural biology has been opened up by advances in imaging techniques. As Schaechter says, we can now "see how an enzyme works or how macromolecules interact with molecules large and small ... single-molecule imaging methods allow us to visualize the tiny movements made and the forces generated by proteins or ribosomes. One can now 'see' in real time polymerases polymerizing and ribosomes translating."

The ability to measure individual molecules in living cells promises new and vivid pictures of signalling within living cells. Experiments and theoretical modelling can now re-engage in a fresh way. Because microscopy and fluorescence labelling now permits the identification, tracking and visualization of the interaction of single proteins or RNA molecules, it is possible to match theoretical models of protein folding or molecular dynamics against what can be seen.

In microbiology, as in other sciences, there are competing interests at work between groups who have commitments to particular methods and tools. Nevertheless, important frontiers in biology and biophysics are being furthered by picturing; data obtained at previously unseeable scales can be translated into vivid visual models that serve to investigate, explicate and illustrate forms and mechanisms. The dimensions are much smaller than those Ehrenberg imagined, but he would have understood the priority accorded to visual tools for understanding function through dynamic structures.

Given this visual turn, it is disappointing to see that the main ASM web pages and those for their General Meeting in Boston, Massachusetts, this week, are visual deserts. Darwinian austerity rules there. Only by following links into Microbe Magazine and Microworld does the visual flourish in the familiar form of the lividly coloured wonders of computer graphics and a series of lively videos.

Among the visual and non-visual cultures in biology, Schaechter has no doubt where the future lies: "The Age of Imaging is just beginning." He does, however, admit that "it's hard to predict where it will lead, as the limits seem to constantly recede".

Martin Kemp is research professor in the history of art at the University of Oxford, OX11PT, UK.

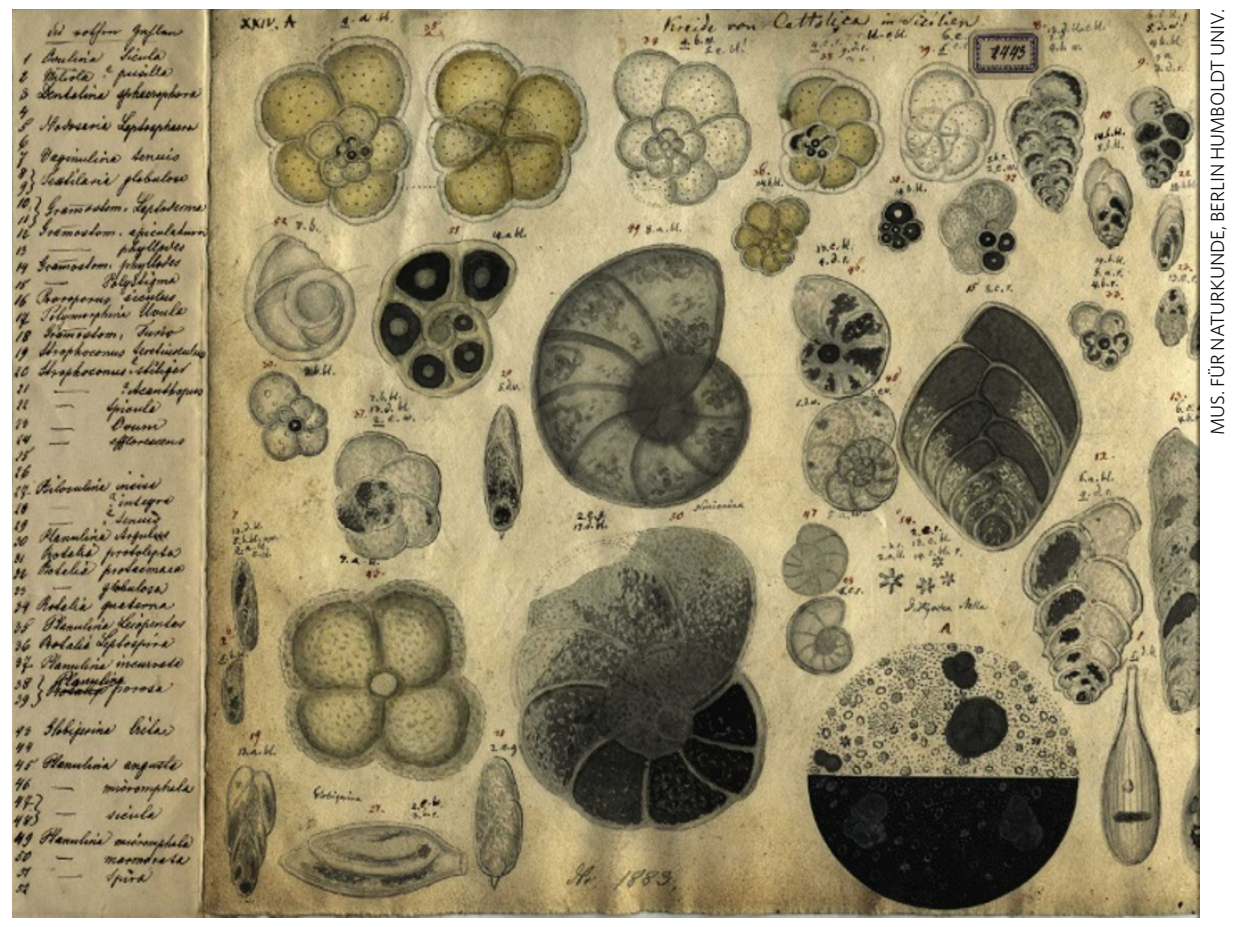

